\title{
Perilaku ibu dalam pemanfaatan persalinan penundaan pemotongan tali pusat sampai 24 jam
}

\author{
Desi Nurlaela Mulyana, ${ }^{1 *}$ Umi Salamah, ${ }^{2}$ Djati Wulan Kusumo ${ }^{3}$ \\ 1, 2Program Studi Kebidanan Program D III STIKes Prima Indonesia, Bekasi - Indonesia, \\ ${ }^{3}$ Program Studi Farmasi Program Sarjana STIKes Prima Indonesia, Bekasi - Indonesia
}

\begin{abstract}
The method of delaying cutting the umbilical cord after the baby is born and letting the cord out completely and then cut after 24 hours has not been implemented in all health facilities. Klinik Utama Anny Rahardjo has been implementing since 2012. The purpose of this research is to know the mother's behavior in the utilization of delivery delay cutting of the umbilical cord up to 24 hours at Klinik Utama Anny Rahardjo East Jakarta in 2017. The method used in this research is a descriptive qualitative method of describing mothers who have utilized this delivery at Klinik Utama Anny Rahardjo. This study amounted to 13 people consisting of 7 informants and 6 key informants. The result of research that mother's behavior is good enough, age, job, distance, and cost don't influence mother's behavior, while education, knowledge, attitude, family support, and health worker influence mother's behavior, in the utilization of delivery delay cord cutting up to 24 hours. It is suggested for Klinik Utama Anny Rahardjo to provide more information so that the mother's knowledge is better, for other researchers it is suggested that the research method use quantitative to get more samples, and for health service to follow up the development of science in the field of this method of delivery.
\end{abstract}

Keywords: the behavior; delay of cord cutting up to 24 hours

Metode persalinan dengan menunda memotong tali pusat setelah bayi lahir dan membiarkan tali pusat keluar secara utuh kemudian dipotong setelah 24 jam, belum diterapkan di seluruh fasilitas kesehatan. Klinik Utama Anny Rahardjo telah menerapkan sejak tahun 2012. Tujuan penelitian ini adalah diketahuinya perilaku ibu dalam pemanfaatan persalinan penundaan pemotongan tali pusat sampai 24 Jam di Klinik Utama Anny Rahardjo Jakarta Timur tahun 2017. Metode yang digunakan dalam penelitian ini adalah metode deskriptif kualitatif yaitu menggambarkan perilaku ibu yang telah memanfaatkan persalinan ini di Klinik Utama Anny Rahardjo. Penelitian ini melibat 13 orang informan, terdiri dari 7 orang informan dan 6 orang informan kunci. Hasil penelitian bahwa perilaku ibu cukup baik, umur, pekerjaan, jarak tempuh dan biaya tidak mempengaruhi perilaku ibu, sedangkan pendidikan, pengetahuan, sikap, dukungan keluarga dan tenaga kesehatan mempengaruhi perilaku ibu, dalam pemanfaatan persalinan penundaan pemotongan tali pusat sampai 24 jam. Disarankan untuk Klinik Utama Anny Rahardjo untuk memberikan informasi lebih banyak lagi agar pengetahuan ibu semakin baik, bagi peneliti lain disarankan agar metode penelitiannya menggunakan kuantitatif agar mendapatkan sampel lebih banyak lagi, serta untuk dinas kesehatan untuk menindaklanjuti perkembangan ilmu pengetahuan di bidang metode persalinan ini.

Kata Kunci: perilaku; penundaan pemotongan tali pusat sampai 24 jam

*Korespondensi Penulis: Desi Nurlaela Mulyana (email: desi88.midwifery@gmail.com), Jl. Raya Babelan No.9,6 KM, RW.6, Kebalen, Babelan, Bekasi, Jawa Barat, 17610. 


\section{Pendahuluan}

Berdasarkan Survei Kesehatan Rumah tangga (SKRT) tahun 2001 menyebutkan prevalensi anemia pada bayi 0-5 tahun sebanyak $45 \%$ (Fredlina \& Malik, 2018). Berdasarkan data Departemen Kesehatan RI, 2007, proporsi penyebab kematian neonatal 0-7 hari tertinggi disebabkan oleh Berat Badan Lahir Rendah (BBLR) yang disebabkan oleh ibu yang mengalami anemia.

Dalam upaya menurunkan AKI dan AKB, Dinas kesehatan menerapkan Asuhan Persalinan Normal (APN) pada setiap persalinan yang dilakukan oleh tenaga kesehatan. APN yang sudah ditetapkan dalam menghadapi persalinan, ada metode terbaru yang dihasilkan dari berkembangnya IImu Pengetahuan dan Kemajuan Teknologi (IPTEK), yang diupayakan bisa menurunkan Angka Kematian Ibu dan Angka Kematian Bayi. Metode terbaru ini adalah Gentle Birth, yaitu persalinan yang tenang, lembut, santun, dan memanfaatkan semua unsur alami dalam tubuh seorang manusia (Aprilia, 2019). Metode ini bebas dari intervensi, dan minim trauma baik pada ibu maupun bayi (Pariani et al., 2018). Pada Gentle Birth, terdapat jenis-jenis persalinan, yaitu Hypno Birth, Water Birth, Silence Birth dan Lotus Birth. (Munawaroh \& Sejati, 2019).

Lotus birth adalah proses persalinan pada kala II yang tidak langsung dilakukan pemotongan tali pusat, tetapi dibiarkan tetap terhubung antara bayi dan placenta hingga puput dengan sendirinya. Rata-rata tali pusat lepas dari perut bayi sekitar 3-10 hari pasca persalinan (Aprilia \& Ritchmond, 2010). Akan tetapi penerapan ini ada yang telah memodifikasi dengan penundaan pemotongan tali pusat sampai 24 jam (Sulistyowati \& Safitri, 2017).

Klinik Utama Anny Rahardjo adalah salah satu klinik bersalin yang berada di wilayah Jakarta timur, telah melakukan pertolongan persalinan dengan metode dengan penundaaan pemotongan tali pusat sampai 24 jam sejak tahun 2012. Sedangkan metode Lotus birth yang murni adalah membiarkan tali pusat lepas dengan sendirinya (Zinsser, 2018).

\section{Metode}

Jenis penelitian ini adalah merupakan penelitian kualitatif jenis penelitian ini merupakan Rapid Assesmen Prosedures (RAP) yaitu penelitian yang dilakukan dalam kurun waktu singkat. Penelitian kualitatif digunakan untuk mengetahui semua informasi dan jawaban mendalam dari seseorang (Notoatmodjo, 2012a), berhubungan dengan pendapat dan perasaanya dalam pemanfaatan persalinan penundaan pemotongan tali pusat sampai 24 jam. Teknik yang digunakan untuk pengumpulan data adalah wawancara mendalam (deep interview).

Instrumen penelitian ini adalah peneliti sendiri dengan menggunakan alat bantu pedoman wawancara berdasarkan tujuan penelitian, catatan lapangan (field note), alat tulis, kamera/ video dan alat perekam suara.

Prinsip kesesuaian adalah informan dipilih berdasarkan pengetahuan yang dimilikinya sesuai dengan topik penelitian. Sedangkan prinsip kecukupan adalah informan dapat menggambarkan secara menyeluruh kejadian yang berkaitan dengan topik penelitian. 
Kuesioner terbuka untuk pedoman wawancara mendalam kepada informan utama dan informan triangulasi. Untuk menguji keabsahan dan kredibilitas data peneliti menggunakan uji triangulasi. Informan utama pada penelitian ini sebanyak 6-10 informan dengan kriteria ibu yang telah melakukan persalinan penundaan pemotongan tali pusat sampai 24 jam di Klinik Utama Anny Rahardjo, kooperatif dan bersedia diwawancarai. Informasi juga didapatkan dari informan kunci yang terdiri dari bidan pelaksana dan pemilik Klinik Utama Anny Rahardjo.

\section{Hasil dan Pembahasan}

Kaitannya dengan kriteria informan dalam penelitian ini adalah ibu yang telah memanfaatkan persalinan persalinan penundaan pemotongan tali pusat selama 24 jam. Informan ini berjumlah 7 orang yang sudah memanfaatkan persalinan persalinan penundaan pemotongan tali pusat selama 24 jam dengan latar pendidikan S2 sebanyak 1 orang, S 1 sebanyak 4 orang, D IV sebanyak 1 orang dan D III sebanyak 1 orang.

\section{Umur}

Informan penelitian ini mempunyai umur yang bervariasi. Ada informan yang termasuk ke dalam Usia Reproduktif yaitu 20-35 tahun (Kusparlina, 2016). Akan tetapi ada juga informan yang tidak termasuk kedalam usia reproduktif yaitu di atas 35 tahun. Akan tetapi ini di dasarkan kepada riwayat persalinan yang keberapa. Semakin dewasa umur informan semakin banyak riwayat persalinan yang pernah dialami informan.

Umur informan mempengaruhi pemahaman dan pola pikir seseorang. Semakin bertambah umur akan semakin berkembang pula pemaham- an dan pola pikir seseorang, sehingga pengetahuan yang diperolah semakin baik (Hansen et al., 2007). Dalam penelitian ini informan sangat bervariasi dalam umur, akan tetapi jika dikaitkan dengan pengetahuan, varibel umur tidak mempengaruhi pengetahuan.

\section{Pendidikan}

Ada 4 informan yang berpendidikan Sarjana, 1 informan berpendidikan Pasca Sarjana, 1 informan berpendidikan Diploma IV dan 1 informan berpendidikan Diploma III. Dilihat dari pendidikan, semua informan berpendidikan tinggi. Mereka memiliki banyak informasi dan akses untuk mendapatkan informasi detail mengenai keputusannya dalam memilih persalinan.

Demikian juga pendidikan semua informan kunci pada penelitian ini berpendidikan tinggi. Ada 4 Bidan pelaksana yang berpendidikan D III Kebidanan dan 1 informan kunci yang sedang melanjutkan pendidikan D IV Kebidanan. Serta 1 informan Kunci yang berpendidikan S2, dimana informan ini adalah Bidan Pengelola di Klinik Utama ini.

Menurut teori bahwa pendidikan merupakan suatu proses perubahan sikap seseorang atau kelompok orang dalam mendewasakan manusia melalui upaya pengajaran dan pelatihan (Notoatmodjo, 2014). Semakin tinggi pendidikan seseorang, maka pola pikir yang dimiliki informan akan mempengaruhi daya nalar dan kemampuannya dalam menganalisis setiap permasalahan menjadi lebih baik. Pendidikan mempengaruhi persepsi seseorang karena dapat membuat seseorang lebih mudah menerima ide-ide atau teknologi baru (Arshinta et al., 2017; Listiani \& Supratman, 2017). 
Para informan dapat mengakses segala informasi yang didapatkan dari pendidkan formal ataupun non formal. Sehingga informan tidak mengalami kesulitan dalam memperoleh informasi dan pengetahuan tentang ilmu atau metode persalinan terbaru. Pengetahuan mengenai pengertian dan manfaat-manfaatnya bisa diperoleh melalui internet, buku, majalah, bahkan dari penyuluhan kesehatan yang dilakukan para tenaga kesehatan. Pendidikan yang tinggi sejalan dengan perilaku yang baik dalam memanfaatkan persalinan ini (Notoatmodjo, 2012b).

\section{Pekerjaan}

Informan pada penelitian ini mempunyai sebagian besar dalam status bekerja, walaupun untuk saat ini sedang dalam kondisi cuti bersalin. Ada 4 informan yang bekerja, 2 informan sebagai Ibu Rumah Tangga (IRT), 1 informan sedang melanjutkan pendidikan D IV Kebidanan. Dilihat dari Pekerjaan, sebagian besar penelitian ini bekerja. Akan tetapi sebagian dari informan pun berstatus IRT, akan tetapi para informan tetap mendapatkan informasi yang baik mengenai keputusan persalinan mereka, didukung dari latar belakang pendidikan.

Dari hasil penelitian sebagian besar informan berstatus bekerja, dalam hal ini para informan dalam posisi cuti melahirkan. Pada informan yang bekerja umumnya diperlukan adanya hubungan sosial dan hubungan dengan orang baik, harus dapat bergaul dengan orang lain, sehingga informan mendapatkan informasi dari teman sejawat maupun atasan.

\section{Pengetahuan}

Berdasarkan pedoman wawancara yang dilakukan peneliti mengenai pertanyaan tenang pengertian, lamanya tali pusat puput, cara tindakan dan manfaatnya di dapatkan hasil bahwa 2 informan dari 7 informan berpengetahuan cukup. Hal ini seperti diungkapkan oleh informan berikut:

"Penundaan memotong tali pusar saja, puputnya 3 hari, dan lebih cepat yang lotus, kalau cara tindakannya tidak langsung di potong, manfaatnya itu daya tahan tubuhnya lebih bagus, kecerdasannya lebih bagus, lebih aktif, tenang, tubuhnya juga lebih kuat" (ibu $6)$.

Sebagian kecil informan belum dapat menjelaskan secara rinci tentang pengertian lotus birth, akan tetapi sebagian besar pengetahuannya tentang pengertiannya disertai dengan alasannya. Untuk beberapa pertanyaan lainnya seperti lamanya puput tali pusat, cara tindakan dan manfaatnya terdapat 5 informan dari 7 informan berpengetahuan baik. Sepeti yang diungkapkan informan sebagai berikut:

"Tali pusatnya tidak langsung di potong, Jadi aliran darahnya itu $60 \%$ masih masuk ke dede nya. Tali pusatnya puputnya kira-kira 6 hari, jadi lebih cepet. Pokoknya tidak langsung dipotong itu tali pusatnnya. Manfaatnya bayinya tidak rewel, udah kering yah ariarinya, tidak takut kuning, lebih cerdas, Lebih sehat dan jarang terkena penyakit gitu. Karena kan dia kekebalan tubuhnya lebih bagus, vitamin dan sisa-sisa dari ari-arinya itu ke transfer ke bayinnya" (ibu 4).

Kesimpulan yang bisa diambil dari wawancara mendalam kepada 2 informan mempunyai pengetahuan cukup dan 5 informan mempunyai pengetahuan yang baik. Hal ini bisa di sesuaikan dengan jawaban informan kunci.

Dirujuk kepada cara mengidentifikasi tingkat pengetahuan Notoatmodjo, 2014 maka informan 
pada studi ini pengetahuannya berada pada tahap pemahaman (comprehension). Para informan memahami pertanyaan yang diajukan peneliti, seperti pengertian singkat, alasan dilakukan persalinan ini, lamanya puput tali pusat serta manfaat-manfaatnya. Akan tetapi ada beberapa informan sebagian kecil tidak dapat menjabarkan definisi secara lengkap. Tetapi tidak mengurangi pemahaman informan lainnya.

\section{Sikap}

Saat wawancara mendalam dengan seluruh informan sebagian besar mengalami kesulitan saat menyusui atau saat memindahkan bayi. $\mathrm{Hal}$ tersebut terjadi karena ibu belum merasakan manfaat penuh penundaan pemotongan tali pusat (Sari, 2016). Untuk pandangan informan mengenai harapan kedepan untuk penerapan persalinan yang telah informan lakukan adalah hampir semua mengatakan hal yang sama, dikaitkan dengan manfaat- manfaat yang telah informan rasakan. Seperti yang telah disampaikan informan sebagai berikut:

"Manfaatnya belum saya rasakan. Kesulitannya saat menyusui, harus dibawa juga plasentanya Jadi agak sulitnya seperti itu jadi harus bener-bener ekstra, harapannya coba ikutin metode yang sama, pasti anemia bayi juga menurun dan dapat menurunkan angka kematian bayi juga di Indonesia" (ibu 1).

Kesimpulan yang di dapat dari hasil wawancara mendalam manfaat yang sudah dirasakan dan kesulitan yang ditemukan bahwa sebagian besar mengalami kesulitan yang sama, selama tali pusat masih tersambung dengan plasentanya. Bahkan sebagian kecil informan mengungkapkan kesulitan- kesulitan itu tidak begitu berarti, berdasarkan pengalaman pada anak sebelumnya. Serta harapan informan terhadap penerapan persalinan ini adalah hampir sama yaitu menujukan sikap yang positif. Akan tetapi sebagian kecil informan tidak mengalami kesulitan karena berdasarkan pengalaman sebelumnya.

Notoatmodjo, 2014 menjelaskan bahwa berdasarkan tingkatan sikap informan ini berdasarkan intensitasnya, termasuk ke dalam tingkatan paling tinggi yaitu, bertanggung jawab (responsible). Sikap responsible adalah bertanggung jawab terhadap apa yang telah diyakininya (Arshinta et al., 2017; Fazayanti et al., 2018). Seseorang yang telah mengambil sikap tertentu berdasarkan keyakinannya, dia harus berani mengambil resiko lain, walaupun masih belum diterapkan di semua fasilitas kesehatan (Green et al., 1980).

\section{Dukungan Keluarga}

Dukungan Keluarga yang diberikan kepada informan bervariatif, akan tetapi pada dasarnya sebagian besar informan merasakan dukungan tersebut (Green et al., 1980). Seperti halnya motivasi, informasi, dukungan mental serta finansial yang diberikan keluarga para informan. Seperti ungkapan indorman sebagai berikut:

"Keluarga mendukung dan tidak khawatir lagi sudah seperti langganan saja. Prosesnya, kualitasnya pokoknya kita udah tau, saya disini keputusan sendiri untuk bersalin disini secara penundaan" (ibu 2).

Karena semua dukungan berupa motivasi, kasih sayang, pemberian informasi, serta keterlibatan dalam pengambilan keputusan telah dirasakan semua informan. Maka peneliti menyimpulkan, sebagian besar informan mendapat 
dukungan dari keluarga yang merupakan dasar keputusan ibu untuk memanfaatkan persalinan ini.

Menurut teori perilaku yang dikemukaan oleh Lawrence Green (1980) bahwa dukungan keluarga memegang peranan penting dalam perubahan perilaku seseorang. Bentuk dukungan yang dapat diberikan seperti kasih sayang, perhatian, pemberian informasi, dukungan moril, keikutsertaan dalam pengambilan keputusan dan dukungan finasial.

\section{Dukungan Tenaga Kesehatan}

Dari hasil wawancara dengan informan, sebagian besar informan mendapatkan dukungan dari tenaga kesehatan dari para bidan pelaksana dan Bidan Pengelola ikut serta dalam memberikan dukungan (Khoniasari et al., 2015). Berikut ini hasil wawancara sebagai berikut:

"Masukan untuk persalinan penundaan ini baik untuk anaknya, manfaatnya penundaan sama yang tidak. Dan selalu dijelaskan setiap kontrol" (ibu 3).

Karena semua dukungan berupa motivasi, kasih sayang, pemberian informasi, serta sikap sabar dan kenyamanan dari informan sangat diperhatikan. Maka peneliti menyimpulkan, sebagian besar informan mendapat dukungan dari tenaga kesehatan yang merupakan dasar keputusan ibu untuk memanfaatkan persalinan ini.

Di dalam teori prilaku yang dikemukakan oleh Lawrence green yaitu salah satu faktor penguat untuk mempengaruhi perilaku informan adalah dukungan dari tenaga kesehatan. Dimana tenaga kesehatan memberikan informasi mendetail mengenai tindakan yang akan diberikan kepada informan, memperlakukan pasien dengan sabar, memberikan kenyamanan selama proses persalinan berlangsung.

\section{Jarak}

Ada beberapa informan yang memiliki jarak tempuh sedikit lebih jauh dengan informan di atas, bahkan mereka tidak masalah mengenai jarak tempuh yang dilalui informan. Berikut ungkapan informan tersebut:

"Seberarnya saya tinggal Bintaro. Luamayan satu jam perjalanan lewat tol. Sekitar 25 KM. karena sudah interest untuk ngelahirin di sini" (ibu 4).

Dari keseluruhan jawaban informan, peneliti dapat menyimpulkan bahwa, jarak tidaklah merupakan suatu hambatan menuju fasilitas kesehatan, dikarenakan informan sudah tertarik dan ingin memanfaatkan persalinan ini.

Menurut Notoatmodjo (2012b) bahwa suatu sikap belum otomatis dapat menjadi tindakan yang nyata diperlukan faktor pendukung atau kondisi yang memungkinkan diantaranya fasilitas. Pada penelitian ini informan memiliki respon yang sangat positif mengenai jarak, karena jarak bukan merupakan masalah bagi para informan.

\section{Biaya}

Hampir semua informan mengatakan biaya yang dikeluarkan sesuai dengan fasilitas yang didapatkan. Seperti hasil wawancara dengan informan sebagai berikut:

"6 juta, kalau dibandingkan sama RS. Pasti ini di bawah. Tapi kalau sama bidan bisa 2-3 kali lipat. Disini juga banyak dapet fasilitas bagus" (ibu 7).

Sedangkan hasil dari wawancara kepada informan kunci, yaitu bidan pengelola RB tersebut menjelaskan dengan detail fasilitas dan apa saja yang diberikan kepada informan. Berikut ini ungkapan dari informan tersebut: 
"Antara sekitar 6 jutaan. Paling murah itu di 5.780.000 paling mahal 6.380.000. itu selama 3 hari. Karena disini itu gini mba, 6 jam setelah persalinan, pasien itu sudah kita perah ASI nya. Sehingga kita bisa melihat bagaimana cara menyusui dengan posisi dan perlekatan yang benar. Kemudian selama disini pun kita ajarkan untuk memandikan bayi, dan pada waktu pulang, wajib memandikan sendiri di bawah pengawasan bidannya. Jadi pasien-pasien di sini itu memandikan bayinya sendiri sampai bisa, dan memerah ASI pun sudah bisa" (bidan pengelola).

Dalam penelitian ini biaya yang dikeluarkan informan sesuai dengan tindakan dan fasilitas ruang rawat inap yang dipilih, menurut terori yang dijelaskan oleh Hansen et al. (2007) adalah termasuk kedalam kelompok biaya variabel (variabel cost) dimana biaya yang jumlah totalnya berubah secara sebanding (proporsional) dengan perubahan volume kegiatan, semakin tinggi volume kegiatan atau aktivitas, maka secara proporsional semakin tinggi pula total biaya variabel. Semakin rendah volume kegiatan, maka secara proporsional semakin rendah pula biaya variabel.

\section{Kesimpulan}

Perilaku ibu dalam pemanfaatan persalinan penundaan pemotongan tali pusat sampai 24 jam ini cukup baik. Umur ibu bukan merupakan faktor yang mempengaruhi ibu dalam pemanfaatan persalinan penundaan pemotongan tali pusat sampai 24 jam. Pendidikan merupakan salah satu faktor pendukung yang mempengaruhi ibu dalam pemanfaatan persalinan penundaan pemotongan tali pusat sampai 24 jam.

Pekerjaan sebagian besar informan penelitian ini sebagian besar dalam status bekerja (cuti melahirkan), pekerjaan bukan merupakan faktor yang mempengaruhi ibu dalam pemanfaatan pesalinan. Pengetahuan Informan yang diteliti mengenai pengertian, lamanya puput tali pusat, cara tindakan dan manfaatnya sebagian besar mempunya pengetahuan yang baik, variabel pengetahuan merupakan faktor yang mempengaruhi ibu dalam pemanfaatan pesalinan penundaan pemotongan tali pusat sampai 24 jam. Sikap dari seluruh informan penelitian menunjukan sikap yang positif terhadap penerapan persalinan penundaan pemotongan tali pusat selama 24 jam ini. Hal ini menunjukan sikap mempengaruhi ibu dalam memanfaatkan persalinan penundaan pemotongan tali pusat sampai 24 jam ini. Dukungan keluarga yang diberikan kepada informan cukup baik. Hal ini merupakan dasar dari sebagian besar informan merasakan dukungan tersebut. Seperti halnya motivasi, kasih sayang, pemberian informasi dan financial. Maka peneliti menyimpulkan bahwa dukungan suami dan keluaga mempengaruhi ibu dalam pemanfaatan persalinan penundaan pemotongan tali pusat sampai 24 jam. Dukungan tenaga kesehatan sangat penting selain dukungan keluarga. Dukungan tenaga kesehatan yang dirasakan informan cukup baik. Maka peneliti menyimpulkan bahwa dukungan tenaga kesehatan mempengaruhi ibu dalam pemanfaatan persalinan penundaan pemotongan tali pusat sampai 24 jam ini. Jarak tempuh informan penelitian ini cukup bervariatif, ada beberapa informan yang memilik jarak tempuh ke fasilitas kesehatan yang dituju yaitu Klinik Utama Anny Rahardjo masih terjangkau, bahkan ada yang jaraknya cukup jauh. Maka dari itu peneliti menyimpulkan bahwa jarak tidak mempengaruhi ibu dalam memanfaatkan persalinan penundaan 
pemotongan tali pusat sampai 24 jam ini. Biaya yang dikeluarkan informan sesuai dengan kebutuhan dan fasilitas yang diberikan, maka dari itu dari penelitian ini bahwa biaya tidak mempengaruhi infoman dalam pemanfaatan persalinan ini.[]

\section{Daftar Pustaka}

Aprilia, Y. (2019). Gentle birth: Cara lembut dan nyaman sambut buah hati. Jakarta: Grasindo.

Aprilia, Y., \& Ritchmond, B. L. (2010). Gentle Birth. Jakarta: Gramedia.

Arshinta, F., Djasuli, M., \& Yuni Rimawati. (2017). Faktor-faktor yang mempengaruhi persepsi etika mahasiswa akuntansi dengan love of money sebagai variabel intervening. Jurnal Keuangan dan Perbankan, 13(2), 128-140.

Depkes RI. (2007). Upaya akselerasi penurunan AKI. Jakarta: Departemen Kesehatan RI.

Fazayanti, D., Galistiani, G. F., \& Juwita, D. R. (2018). Peer education sebagai upaya promkes apoteker untuk meningkatkan pengetahuan dan sikap pelajar SMK di Kota Tegal mengenai pencegahan penyalahgunaan narkoba. Universitas Muhammadiyah Purwokerto.

Fredlina, J., \& Malik, R. (2018). Hubungan status gizi terhadap anemia pada balita di Kelurahan Tomang Kecamatan Grogol Petamburan Jakarta Barat periode Januari 2015. Tarumanagara Medical Journal, 1(1), 110115. https://doi.org/10.24912/tmj.v1i1.2523

Green, L. W., Kreuter, M. W., Deeds, S., \& Partridge, K. (1980). Health education planning: A diagnostic approach. California: Mayfield Publishing Company.
Hansen, D., Mowen, M., \& Guan, L. (2007). Cost management accounting and control. Boston: Cengage Learning Acquisitions, Inc.

Khoniasari, A., Murti, B., \& Dewi, Y. L. R. (2015). Pengaruh paritas, pengetahuan ibu, dukungan keluarga, dan peran tenaga kesehatan terhadap pelaksanaan inisiasi menyusu dini di RSUD Salatiga. PascasarjanaIKM Universitas Sebelas Maret.

Kusparlina, E. P. (2016). Hubungan antara umur dan status gizi ibu berdasarkan ukuran lingkar lengan atas dengan jenis BBLR. Jurnal Penelitian Kesehatan Suara Forikes, 7(1), 2126. https://doi.org/10.33846/sf.v7i1.8

Listiani, I., \& Supratman, S. (2017). Hubungan tingkat pendidikan dan penghasilan pasien dengan persepsi pasien tentang mutu pelayanan kesehatan di Puskesmas Baki Kabupaten Sukoharjo. Universitas Muhammadiyah Surakarta.

Munawaroh, M., \& Sejati, A. R. (2019). Pengaruh penundaan pemotongan tali pusat terhadap lama lahir plasenta, lama puput tali pusat dan keberhasilan inisiasi menyusu dini (IMD) di RB Anny Rahardjo dan RB Rosnawati Jakarta Timur. Jurnal IImiah Kesehatan, 10(1), 53-57. https://doi.org/10.37012/jik.v10i1.16

Notoatmodjo, S. (2012a). Metodologi Penelitian Kesehatan. Jakarta: Rineka Cipta.

Notoatmodjo, S. (2012b). Promosi kesehatan dan perilaku kesehatan. Jakarta: Rineka Cipta.

Notoatmodjo, S. (2014). Ilmu Perilaku Kesehatan. Jakarta: Rineka Cipta.

Pariani, N. L. D., Dewi, Y. T. N., \& Hartanto, H. (2018). Perlindungan hukum bagi bidan dalam praktik pelayanan metode persalinan gentle birth di Provinsi Jawa Tengah. Unika Soegijapranata Semarang. 
Sari, N. A. P. (2016). Penundaan penjepitan dan pemotongan tali pusat pada bayi Ny. $Y$ di BPM C. Retno Wahyuningsih Kecamatan Ayah Kabupaten Kebumen. STIKES Muhammadiyah Gombong.

Sulistyowati, N., \& Safitri, W. (2017). Hubungan pengetahuan dengan sikap bidan dalam penatalaksanaan penundaan pemotongan tali pusat di Puskesmas Poned Kota Tanjung Pinang. Jurnal Komunikasi Kesehatan, 8(2), 110.

Zinsser, L. A. (2018). Lotus birth, a holistic approach on physiological cord clamping. Women and Birth, 31(2), e73-e76. https://doi.org/ 10.1016/j.wombi.2017.08.127 
The page was intentionally left blank. 